\title{
POR LA HUMILDE AVENTURA: CRÍTICA Y CRISIS EN LA LÍRICA TEMPRANA DE SALVADOR ESPRIU
}

\author{
THROUGH THE HUMBLE ADVENTURE: CRITIQUE AND CRISIS IN \\ SALVADOR ESPRIU'S EARLY POETRY
}

\author{
Antonio MÉNDEZ RUBIO \\ Universitat de València
}

\begin{abstract}
Resumen: La poesía lírica de Salvador Espriu es un terreno favorable para estudiar las relaciones críticas entre texto y contexto, entre literatura y poder. Este artículo plantea cómo este modo de escritura, especialmente hacia mitad del siglo XX, juega con un conjunto muy amplio de sentidos y códigos de lectura, de manera que (pre)figura una serie abierta de claves en el momento de la recepción cultural. Connotación, simbolismo y musicalidad influyen aquí simultáneamente como recursos principales para proponer una nueva y arriesgada forma de entender la política del poema y sus posibles efectos sociales.
\end{abstract}

Palabras clave: Poesía / política / crisis / canon / poder

Abstract: The Salvador Espriu's lyrical poetry is a favorable ground in order to study the relationship between text and context, literature and power. This article sets how this mode of writing, specially around the middle of twentieth century, plays with a very broad set of meanings and codes of seading, so it (pre)figures an open series of keys at the time of cultural reception. Connotation, symbolism and musicality simultaneously influence here as main resources to propose and new and risky form of understanding politics of poem and his possible social effect.

Keywords: Poetry / politics / crisis / canon / power 
De entre todas las manifestaciones discursivas consideradas internas a la institución Literatura, la poesía es desde luego la más resistente a un análisis de sus relaciones con la realidad social. El carácter connotativo o simbólico, cuando no abiertamente alegórico o arreferencial, hacen de la poesía lírica un terreno especialmente resbaladizo a la hora de abordar sus relaciones con las formas de poder establecidas en nuestro mundo. Sin embargo, una concepción del poder que atraviese y desborde las fronteras pragmáticas del Estado y se adentre en los circuitos del sentido y la semiosis colectiva podría ayudar a desbloquear estas dificultades críticas. Desde la perspectiva de Michel Foucault, de entrada, "el poder consiste en relaciones complejas: esas relaciones implican un conjunto de técnicas racionales, y la eficiencia de esas técnicas es debida a una sutil integración de tecnologías de coerción y tecnologías del sí" (Foucault 2015: 148). En este sentido, las tecnologías del sí o del yo, en tanto modos ideológicos y biopolíticos de subjetivación, constituyen un espacio abierto de indagación para el avance en la comprensión de las relaciones multidimensionales entre poesía y poder.

De hecho, la poesía podría así conectarse con la concepción de una literatura menor defendida por Deleuze y Guattari (1978). Se trataría de una literatura menor no por tratarse de un idioma minoritario sino por tratarse de una práctica minoritaria dentro de un campo dominado por otros códigos o cánones. Y es precisamente por esa condición menor por la que, a su vez, "su espacio reducido hace que cada problema individual se conecte de inmediato con la política" (Deleuze / Guattari 1978: 29). Por esta razón, vista desde este ángulo, se puede decir también y radicalmente de la poesía que en ella "el campo político ha contaminado cualquier enunciado" (1978: 31). Al llegar a este punto, sin embargo, la escritura o práctica poética son tomadas desde una óptica más amplia y compleja de la que suele caracterizar a la hermenéutica literaria. Asociando la práctica poética a la idea una literatura menor, en fin, no estaríamos ante una cuestión técnicamente literaria sino que, en la línea filosófica de Deleuze y Guattari (1978: 65), a esto ya no se le puede llamar "de ninguna manera literatura, sino que la enunciación y el deseo son una y la misma cosa, por encima de las leyes, de los Estados, de los regímenes. Sin embargo: enunciación siempre histórica, política y social. Una micropolítica, una política del deseo, que cuestiona todas las instancias”. La poesía, en fin, como a continuación se aborda a propósito de Salvador Espriu, desterritorializa las relaciones de poder al tiempo que las politiza en una clave crítica singular, deseante, enunciativa. 
Tal vez nada ha hecho tanto daño a la poesía moderna como la idea de vincularla (hasta reducirla) a la expresión del yo. De acuerdo con las premisas instrumentales de la racionalidad liberal, que la primera Escuela de Frankfurt llamaba razón instrumental, el mundo se representa a sí mismo a partir de la relación ideal que mantiene un sujeto autoconsciente y autónomo con una serie de objetos disponibles, que se ofrecen como medios para la consecución de un determinado fin. Siguiendo el esquema prototípico que articula la narración de Daniel Defoe en su clásico Robinson Crusoe (1719), un individuo autosuficiente explora un mundo nuevo entendido como territorio conquistable y apropiable, guiado por una mentalidad utilitarista y totalizadora. Por otra parte, esta confianza en la existencia de individuos autónomos que mantienen entre sí relaciones libres y que entienden su entorno como un espacio para la apropiación y la acumulación indefinida de bienes se vería impulsada en Europa por la Revolución Industrial y la difusión intensiva de argumentos como los recogidos en el célebre ensayo de Adam Smith titulado La riqueza de las naciones (1776). Así, la institución de un Sujeto pensante, separado e idealizado, de Descartes a Hegel, avanza por la filosofía occidental con su marcha triunfal, con una arrogancia ciega a sus marcas ideológicas de clase, género y raza, dentro de un contexto etnocéntrico y colonial que legitimaba (y se veía legitimado por) un chip de estas características.

En los debates filosóficos y estéticos del siglo XIX la pervivencia de una estructura metafísica de pensamiento ayudó, en fin, a reforzar el juicio que veía en el lenguaje un medio cognitivo y expresivo en manos de un sujeto capaz de controlarlo y manejarlo según sus propios conceptos, sus propios objetivos, sus propios intereses. El recurso a la poesía lírica se reserva entonces, en este sentido, para un uso desinteresado o sentimental del lenguaje, que así cumpliría con la función de excepción que se venía atribuyendo al fenómeno artístico como mínimo desde Kant. En otras palabras, la poesía podía así seguir adecuándose al dictado platónico-aristotélico de quedar asimilada por la filosofía y sus mecanismos idealizantes y miméticos. Sin embargo, desde F. Schiller y F. Schlegel, este acto de violencia será contrarrestado por una concepción romántica reflexiva, sumergida, que desfonda infinitamente la subjetivación del lenguaje y de la realidad. De esta forma, la filosofía y la poesía buscaban reencontrarse en su mutuo esfuerzo por renovar la responsabilidad individual y social, política y moral, en virtud de una concepción libertaria y creativa del lenguaje. Pero es cierto que, durante todo el siglo XX, el afán racionalista y cientifista ha calado incluso en el sentido común, y ha instalado en las discusiones sobre arte y literatura una diferencia lógica entre realidad y lenguaje que sigue paralizando el avance de una concepción crítica de la poesía. 
Sobre la base de validez indiscutida que implica el principio de verificación se descalifica la función de la poesía, se le expropia de cualquier valor de verdad, y se la relega de modo paternalista al limbo de la ingenuidad y la inutilidad sin remedio. Esta inercia positivista ha expandido una especie de mandato superyoico, culpabilizador, que asume la práctica poética a regañadientes, bajo el manto de una mala conciencia que por momentos se vuelve irrespirable, injustificable, no solamente para quien piensa o lee poesía sino para quien la practica de una forma o de otra. Aun así, el pulso utópico y libertario de la poesía no ha renunciado a seguir entreviéndose o entreoyéndose como un pulso intersticial, un intervalo tan proliferante como secreto. Como ya sugería Novalis en Los discípulos en Sais (1798), la poesía trabaja con el límite de la conciencia y de los significados, vuelve productivo y desafiante el desconocimiento, "encarna la magia de una forma oscura, tiene el poder de encantamiento de la lengua" (2004: 289). Como se sabe, Novalis escribía a partir de su lectura de otro poeta y pensador, Friedrich Schiller, quien, en Sobre poesía ingenua y sentimental (1795) planteaba una distinción táctica entre poesía atemática o musical (musikalisch) y poesía figurativa o plástica (plastisch), para, desde ahí, incidir en cómo "lo musical supone la tendencia atemática de aquellos poemas cuya configuración u orquestación formal provoca un estado de ánimo paralelo al temple sentimental, esto es, a una sentimentalische Stimmung que desborda los límites de lo figurativo o lo representacional" (Cuesta Abad 2010: 79). La condición musical suspende el encaje ideal de significantes y significados: pone en crisis mediante el juego de la forma la supuesta definición convencional de la realidad como entidad compacta, apriorística, y del lenguaje como mera manifestación o epifenómeno de lo real.

Así pues, en torno a una palabra en realidad tan resistente a la comprensión como la palabra forma gira un ámbito de preguntas todavía pendientes. Por supuesto, esas preguntas no incumben solamente a la cuestión subjetiva o poética sino también, y a la vez, a la cuestión social o política -no en vano, a propósito de Kafka, mostraba polémicamente Adorno (1992: 302) que "en su lenguaje se concreta la afirmación de que la forma es el lugar del contenido social de las obras de arte". En un ensayo original de 1960, que a menudo parece poco tenido en cuenta, R. Jakobson entendía por función poética no aquella mediante la cual el lenguaje se centra en el emisor (expresiva), el receptor (conativa), el contexto (referencial), el contacto (fática) o el código (metalingüística), sino más bien "la tendencia hacia el mensaje como tal (Einstellung), que no puede estudiarse con efectividad si se la aparta de los problemas generales del lenguaje", añadiendo a continuación que "cualquier intento encaminado de reducirla a poesía, o viceversa, constituiría una forma engañosa de simplificar las cosas" (Jakobson 1985: 37). La poesía trabajaría la dimensión sensorial, corporal, del lenguaje tanto en su ritmo, como en su articulación sintáctica y su sonoridad para así abrir en las palabras "un 
90 Tropelías. Revista de Teoría de la Literatura y Literatura Comparada, número extraordinario 4 (2018) Antonio Méndez Rubio

tiempo musical" (Jakobson 1985: 41). No obstante, los códigos más extendidos a la hora de interpretar el valor de la poesía descuidan esta condición musical de la lírica, y no es forzado entender que así sea debido a la provocación que la lírica supone para los dispositivos autoritarios de enunciación que focalizan el poder incontestable, logocéntrico, de una u otra Idea.

Como ocurría en Platón, la poesía se ve entonces arrojada a una extraterritorialidad que, al mismo tiempo, la poesía convierte en un motivo de insumisión y libertad. Esta tierra de nadie no es otra que lo otro, es decir, el no-lugar donde la alteridad inscribe su energía transformadora como condición de creatividad, de vida. En este punto sin clausura, la prepotencia tradicional del Yo se ve cuestionada no porque el Yo desparezca sin más sino porque desaparece su carácter omniabarcante, arrollador. En palabras de J. M. Cuesta Abad: "Lo lírico es la inscripción de un instante de tensión atencional en las palabras: ellas mismas otras que ellas mismas por obra de una voz sin figura" (2010: 160). La intervención espectral de una "voz sin figura" actúa como un vaciamiento, como un espaciamiento: hace sitio, deja espacio libre al destituir de su trono el concepto de Sujeto como principio ordenador de todas las cosas. Tal como se ha pensado en la tradición clásica occidental, de hecho, el concepto "yo" se vuelve inviable (Piera 2012: 36). Evidentemente, esto supone una especie de crisis del lenguaje que se vuelve singularmente necesaria para asumir y encarar un mundo en crisis.

Esta serie de interrogantes y provocaciones toman cuerpo poético en la lírica temprana de Salvador Espriu, muy especialmente en las colecciones de poemas del período 1946-1955: Cementerio de Sinera (1946), Las horas (1951), Mrs. Death (1952), El caminante y el muro (1954) y Final del laberinto (1955). En esta zona de la obra espriuana se forma una red descentrada de motivos que destituye al Sujeto-Yo como motor absoluto y lo resitúa en clave lírico-musical dentro de una constelación abierta y abismada de sentidos. Términos como muerte (mort), sueño (somni), canto (càntic) o silencio (silenci), entre otros, son marcas de la intensidad que llega a alcanzar en Espriu esta experiencia crítica y creativa. Así mismo, esta perspectiva crítica confiere una capacidad de perforación y desestabilización a la poética de Espriu en su conjunto que no suele ser relevante en la imagen pública o canónica de esta poesía. Y no es extraño: es justamente el carácter lírico de esta poesía lo que impide que cristalice en torno a ella una doxa que se olvide del componente de aventura, de crítica y de humildad que dicha poesía propone. Y si esa doxa pudiera cristalizar en algún momento lo haría, por tanto, como una forma de neutralización violenta del reto poético que suponen los poemas de Salvador Espriu. Si el estudio de la lírica y la función poética ayuda a entender que "el yo lírico permite que la función de ese yo quede a cargo de signos que no tienen 
nada que ver con los usos familiares de la palabra yo" (Piera 2012: 23) entonces se sigue de aquí que, como escribe C. Piera, el triunfo de la lírica es, en efecto, "la derrota del autor" (2012: 124). Y esta derrota del autor podría también estar siendo la derrota de quienes han utilizado la imagen del autor como pivote para reforzar imágenes más o menos inerciales de un mundo demasiado previsible, convencional, demasiado fácil de reconocer.

Contando con su tono tentativo, inaugural, Cementerio de Sinera (1946) es un poemario ya receptivo al contraste entre la expresividad/subjetividad (intencional) y la materialidad/precariedad (atencional) de la escritura sobre la página en blanco. El poema va aprendiendo a darse como un espacio vaciado y a la vez concreto, inminente, atravesado por la necesidad no tanto de dejar algo dicho como de que el poema sea algo que se pueda, por fin, decir. Pero la insuficiencia del sujeto organiza ya obsesivamente la columna vertebral de la enunciación en Las horas (1951). En pleno ecuador del siglo XX, se diría que el recurso a la ausencia y la muerte está dispuesto en Espriu para presentarse como esa forma de perforación del sentido que G. Wajcman ha denominado "el objeto del siglo" (2001).

En cierta manera, es como si el sujeto pudiera asistir a su propia muerte (como una forma viva de no-sujeción). Así al menos puede leerse el poema de Las horas titulado "Noche": "Palidez. Con ávidos / labios de nieve, ahondado, / más cántico suplicas... cuando te vas quedando inmóvil, / sin retorno del aire...”. El poema "En tu muerte" incide en esta evanescencia del Yo-Tú, y en cómo esta forma de muerte acarrea una disolución de los límites de la realidad, de modo que tanto el Sujeto como el Objeto se ven inmersos en una espiral callada de dolor y de imposibilidad. El decir lírico se entiende aquí como una apertura del espacio donde toda huella desaparece: "Contemplo sin pesar / mi paso que se borra" termina diciéndose en "Bajo la lluvia". Esta operación disolvente podría enlazarse con la tesis de una escritura del desastre argumentada por M. Blanchot (1987). Para Blanchot, se da en la escritura poética una desindividualización motivada por una inesperada responsabilidad que desprende al yo del yo. Esta responsabilidad tiene que ver con la experiencia de la otredad que interpela como un "secreto sin rostro" (1987: 34). Espriu parece el referente exacto de Blanchot cuando éste anota que "escribe bajo la atracción de lo real imposible, aquella parte de desastre en que zozobra, a salvo e intacta, toda realidad" (1987: 39). Se diría que esta lírica temprana de Salvador Espriu está volcada en una labor lenta, paciente, en virtud de la cual todo lo que se 
92 Tropelías. Revista de Teoría de la Literatura y Literatura Comparada, número extraordinario 4 (2018) Antonio Méndez Rubio

muestra o se dice queda cuestionado por su propia invisibilidad, por esa experiencia de la muerte que no puede sino ser una muerte de la experiencia, es decir, de la experiencia que reconocemos en torno a los principios ordenadores de realidad e identidad. La ambientación nocturna podría, en fin, remitir a la oscuridad de lo imposible señalada por Blanchot (1987: 49): "Sentimos que no puede haber experiencia del desastre, aunque lo entendiéramos como experiencia última. Éste es uno de sus rasgos: destituye cualquier experiencia, le quita autoridad, está velando sólo cuando la noche vela y no vigila".

En una clave que recuerda la confianza de Mallarmé (2002: 126) en "la desaparición elocutoria del poeta", el decir poético se convierte en un cristal oscuro, nocturno, donde la identidad del sujeto y la objetividad de lo real se diluyen dando paso a una emergencia ciega de lo real (o, en sentido lacaniano, de lo real-real). Paradójicamente, la tematización del canto y la música se canaliza mediante el susurro, rumor o apenas ruido que supone una textualidad confrontada con su propia inviabilidad semántica y pragmática, esto es, una poesía del desastre.

En concreto, las partes segunda y tercera de Las horas son el escenario de una crisis que se vuelve respiratoria como un "vuelo libre de aves". El precio que se ha cobrado esta libertad es sencillamente el precio de la destrucción: "Sólo sonrío y pienso / en destruir el nombre / con el silencio". Piezas como por ejemplo "Prometeo", "Omnis fortasse moriar" o "Libre vuelo" insisten en delinear este intenso pulso de dolor y a la vez de liberación. Se adivina ahí una sensación aérea de desnudez, de temblor inaugural, de luz que asoma entre las grietas de tanta sombra. La fragilidad ante la derrota deja asomar su reverso indócil: el del vuelo mínimo, precario, que inesperadamente la pérdida hace ahora posible: "Desnuda, derrotada / por el brillo del alba, / la viajera / llena de crímenes, inútil / y tembloroso vuelo, falena." Estos versos componen un breve poema sintomático. Lleva por título "Psyché". Se puede entender, así, que la cuestión de la subjetividad está aquí jugando el papel de motto y de mecha que ha de prender de forma necesaria en la lectura. El diálogo entre la referencia a Psyché y una lectura psicoanalítica está, de hecho, y por decir así, cantado. Siguiendo el relato mitológico griego, a Psyché se le aparece Eros, su amante, solamente de noche, puesto que es la noche la que impide el reconocimiento, la identificación, al tiempo que activa los mecanismos imparables y magnéticos del deseo. Nocturnidad y deseo (vivido como imposible) son para Freud, de hecho, los ingredientes motivadores del sueño. De ahí la conocida tesis de Freud en el sentido de que "el sueño es la realización (disfrazada) de un deseo reprimido" (2011, I: 201). Y de esto, a su vez, se podría seguir razonablemente que "el sueño nos demuestra que lo reprimido perdura también en los hombres normales y puede desarrollar funciones psíquicas. (...) La 
interpretación onírica es la vía regia para el conocimiento de lo inconsciente en la vida anímica" (Freud 2011, II: 304).

En este punto, pues, el análisis freudiano ayuda a comprender cómo la muerte del Yo, entendida ésta como fractura o puesta en suspenso del orden simbólico, propicia fisuras para la irrupción de las pulsiones inconscientes. No en vano, desde Homero, Psyché sale volando como una mariposa de la boca de quien muere. No hay duda de que el uso que Espriu hace de este motivo mitológico clásico se presta a una hermenéutica sublimada. Al mismo tiempo, sin embargo, cuando este motivo se articula con una lírica destructiva, o del desastre, adopta de pronto los rasgos oníricos de un espectro, de un fantasma cuando menos inquietante. Pero es justamente esta inquietud o experiencia de crisis (indicio de una radical crisis de experiencia) lo que la crítica ha tendido a desatender en Espriu, o bien a entender más como un ítem temático, enunciado, que como una imposibilidad inscrita en el espacio inseguro de la enunciación. Sin ir más lejos, piénsese en cómo el prestigioso estudio de Josep M. Castellet Iniciació a la poesia de Salvador Espriu (1978, original de 1971) definía la muerte como el "gran tema espriuà" (1978: 30) para, acto seguido, situar la poesía de Espriu dentro de un canon estético intemporal y universalista identificado por Castellet (1978: 90) como "la constel.lació de les grans creacions de la humanitat". Este argumento probaría "la vinculació d'Espriu a tota la gran tradició literària i espiritual de la humanitat". Y así sucesivamente.

Leída así, resulta lógico que la canonización de la poesía de Espriu cristalizara no con poemarios tempranos como Las horas (1951), Mrs. Death (1952) o El caminante y el muro (1954), sino con el viraje de esta poesía hacia una poética que, especialmente desde La piel de toro (1960) en adelante, pondría más énfasis en el simbolismo declarativo y la continuidad sintáctica. A lo largo de los años sesenta, y quizá hasta Formas y palabras (1974), donde se replantean sintéticamente las preguntas pendientes de una lírica abismada (en la muerte, el silencio, lo sin-rostro), Espriu trabaja con esquemas expresivos más orientados al reconocimiento del sentido que a su autocrítica. El pasaje de Castellet, una vez más, resulta ilustrativo: "sobre la base d'una meditació de la mort, el poeta havia construït una obra que, progressivament, havia adquirit un elevat to civil, després d'una presa de consciencia histórica -amb La pell de brau- que havia esvaït els fantasmes anteriors" (1978: 13). Se aprecia con claridad cómo un crítico tan influyente como Castellet saluda La pell de brau como el feliz punto de inflexión (de "toma de conciencia") que deja atrás una poesía abstracta o fantasmática para adentrarse en la reivindicación crítica y política. Así pues, lo que se deduce de Castellet es que Espriu da un paso hacia la poesía civil o política (presuponiendo entonces que su poesía temprana no lo era o no tanto) y no que ese paso sea un desplazamiento desde una forma a otra de entender la 
94 Tropelías. Revista de Teoría de la Literatura y Literatura Comparada, número extraordinario 4 (2018) Antonio Méndez Rubio

crítica poética y política de su tiempo. Por lo demás, el afán de Castellet por vincular esta poesía con códigos míticos se sustenta más, en efecto, en los libros publicados por Espriu en la década de 1960 que en esa lírica temprana que el poeta caracterizó como una "humilde aventura".

El fecundo diálogo que la poesía de Espriu mantiene con fuentes bíblicas, la mística judía o algunas leyendas egipcias se interpreta, en fin, como voluntad de situar lo poético en el orden de lo mítico para, desde ahí, defender la forma que Espriu tuvo de entender la crítica social. Haciendo esto, la crítica literaria resalta elementos propios del texto poético (mito solar, mito del laberinto, Teseo...) con vistas a componer un código de lectura sobresignificante que asfixia los textos y que, en relación con los textos escritos por Espriu antes de 1960, llega a silenciar su carga lírica y crítica, sacrificándola en el altar de una "conciencia histórica" que a fin de cuentas es solamente una manera entre otras de entender la representación de lo real en el discurso poético. En última instancia, la clave mitificante que, sin duda, funciona en Espriu como una táctica de denuncia política que eludiera hasta cierto punto la vigilancia y la censura fascista, exige del poema como contraprestación una cierta saturación semántica que contraviene (o contrapesa) el deseo de aire, de vuelo, que venía ejercitándose en los poemas de 1950. En el plano de la poesía lírica de Espriu esta tensión aparece y reaparece como un foco de conflicto constante. En el plano de las lecturas canónicas de esta poesía, no obstante, puede que esta ambigüedad se haya visto potenciada por un hincapié en el archivalor del código mítico, sobre cuyo efecto acrítico y congelante ya advirtió R. Barthes (Mitologías, 1957) precisamente en esa misma época.

\section{4}

La zona de manifestación más sensible y descarnada de este conflicto poético y político tiene que ver, en suma, con el problema de la lengua en Espriu. Espriu concibe simultáneamente el lenguaje (la lengua, las palabras, los nombres, el silencio...) como lengua catalana (“del meu vell català", "llavis catalans", "la meva llengua"...). Se dan así a la vez dos cuestiones que, yendo unidas, no se reducen sin más a mera unidad: de una parte, a la manera de la función poética según Jakobson, el poema remite a su propia forma linguística para realizarse como tal poema; de otra, y al mismo tiempo, esa práctica de escritura se ancla en un idioma históricamente determinado y maltratado. Dos frecuencias fenoménicas se cruzan entonces provocando una especie de onda expansiva, no reducible a interpretaciones unívocas o lineales. La frecuencia más explícitamente política se aproxima conscientemente (por "consciencia histórica") a diversas variantes ideológicas 
del catalanismo o del nacionalismo. La frecuencia más implícitamente poética reflexiona críticamente sobre la relación entre lenguaje y realidad, perforando los principios de legitimación que lo real impone, como sería el caso de la identidad de nominación ("Me gustaría decirlo con mis labios de ciego"), la autoridad simbólica (“Un hombre flaco de Meir”) o la subjetividad hegemónica (“El monigote”). En Mrs. Death (1952), la soledad de un monigote "al que lluvias / devorarán el rostro" se confunde así con la voz de los esclavos, de los fugitivos, de los muertos y los desesperados que atraviesan como espectros "la humilde aventura / de trenes y calles negras" ("Canción de Llundun"). Desde luego, con esto se nos puede remitir a una historia colectiva de clandestinidad y represión. Con todo, se hace más complicado trasladar esta referencia a una ideología nacionalista (catalana, o española, o del tipo que sea), entendida como identidad de origen y destino que comparte una comunidad de sujetos, cuando las premisas que operan en este discurso ideológico (o dispositivo, por decirlo con Foucault) se apoyan en valores (identidad, origen, sujeto, realidad...) que los poemas abordan una y otra vez desde una interrogación incesante.

En este sentido, hay como mínimo un doble nivel de lectura de esta cuestión de la lengua en Espriu: podría decirse que están activándose, y en cruce, una lectura manifiesta y una lectura secreta. En la primera, la lengua (catalana) es tanto un medio de vida como un objeto de consideración reivindicativa en los poemas. En este nivel de lectura manifiesta la lengua entronca con el contexto específico del autor y actúa como un potente mecanismo de referencialidad e identidad. En este nivel la recepción de Espriu se ha sentido cómoda con frecuencia a la hora de confundir autor (contexto) y sujeto poético (texto), de modo que ambos se mezclan indiscriminadamente a la hora de celebrar que "els seus poemes i contes presenten trossets de vida, de veritat" (Prats Sobrepere 1992: 18). De la misma forma, la lengua de Espriu se toma así como sinécdoque del habla de un pueblo, de la misma manera que las referencias a su lugar de vida infantil (Sinera/Arenys de Mar) se toman como sinécdoques del territorio geográfico catalán: "Parla-Poble, una perfecta simbiosi en el davallar de la historia que ens ha fet diferents d'altres pobles i cultures. Bé prou que ho sabem: perdre la parla suposa perdre la identitat" (Móra 1992: 11). Se lee entonces la poesía espriuana como un medio identitario de reconocimiento colectivo. Sinera se trata como un pueblo edénico, idealizado, que actúa como metonimia de la patria. Tanto es así que incluso se ha publicado recientemente una reedición de La pell de brau acompañada de textos firmados por diferentes "analistas políticos" (Barcelona, Columna, 2010).

De nuevo aquí reaparece en la doxa hermenéutica la importancia de la clave mítica para entender esta poética, incluso muchas veces a pesar de declaraciones expresas del propio Espriu, 
96 Tropelías. Revista de Teoría de la Literatura y Literatura Comparada, número extraordinario 4 (2018) Antonio Méndez Rubio

quien se esforzó por restar relevancia a esa dimensión de su poesía considerándola apenas “un recurso estilístico" (en Batista 1985: 41). Aún en vida, el poeta declara en entrevista con Antoni Batista (1985: 29) que “La pell de brau no té res a veure amb el que després n'han dit poesia social, sinó que és una poesia estrictament cívica i tan lírica, dintre de tot, com jo vaig poder aconseguir”. Las palabras de Espriu denotan un esfuerzo no por desmarcar totalmente, desde luego, pero sí por distanciar su poesía de un uso político meramente instrumental. Y esto, hay que insistir quizá, no tanto por un olvido de lo político como tal (que no es congruente con la condición social de todo discurso, incluido el discurso lírico) sino por un empeño en recuperar para la opinión pública la dimensión radicalmente poética y lírica de una cuestión que, siendo política, lo es de un modo muy alejado (y tal vez más radical y más decisivo) de lo que convencionalmente se entiende por política. Este pliegue lírico de la crítica sociopolítica vuelve la escritura irónica, destructiva en sentido benjaminiano (Méndez Rubio 2008), como así puede ocurrir en un poema-síntoma como "El funámbulo" (Mrs. Death, 1952): "peregrino en la cuerda / del arco en el abismo, / traje vasos de agua, / sin derramarlos, desde / el angustioso origen / de los ojos hasta / donde acaba cualquier / deseo de paisaje. / (...) Pero aplaudisteis mientras / di cuenta del trabajo. / Pues no faltó una gota / a la sed de los diablos".

En esta línea reivindicativa de otra política, donde se incorporara críticamente al debate la experiencia poética, podría quizá entenderse de otra forma la apuesta que hace la lírica temprana de Espriu por una poesía del desastre. La condición poética, lírica o musical de esta escritura conduce a prestar más atención a ese otro nivel de lectura implícita, o lectura secreta, nocturna, donde el vínculo con el contexto social ni se debilita ni se desvanece sino que, antes bien, se reformula en una frecuencia de onda que pone en crisis las nociones convencionales de realidad o identidad, su supuesta estabilidad o fijeza, su presunta autoridad. El término Sepharad, por ejemplo, remite tanto a un referente incontestable (la realidad de la Península Ibérica, convocada en su fase histórica prenacional) como a sí mismo, es decir, a un significante diaspórico, alucinado, dividido (Sepharad / separar). El poema XIV de Libro de Sinera (1963), en pleno ciclo de "conciencia histórica", se abre a la oscuridad sin sitio, a la llamada de la muerte, de un modo que había sido preparado por los poemarios anteriores, "fantasmáticos”, de Espriu, y que aquí renace como un ritornelo ciego: “A tientas, noche. / Si te sientes presa segura, / ¿a dónde huir? // Cuando te señale el dedo, / para entrarte en la sombra, / di que sí".

Cuando en este momento se vuelve a hablar de muerte, claro está, se haría en el sentido de falta en el orden de lo simbólico, de ausencia que es a su vez huella de lo real, de fín o límite de la 
experiencia lírica y vital. Se habla así, como se ha subrayado, en un nivel de lectura latente, no explícito, capaz sin embargo de conectar con la dimensión inconsciente del lenguaje en juego. La cadena significante deja sentir sus fisuras de sombra, lo que J. Lacan llamara "los huecos del sentido" (Lacan 2009: 762). En esas fisuras que la lírica trabaja como lenguaje abismado, liberado de la carga temática o referencial, se asiste entonces a un momento de fading o desaparición del sujeto y del objeto, del Yo y la Realidad, o más bien, a la destrucción de lo que el Yo (sujeto) entiende por Realidad (objeto). Se cumple de este modo el dictum lacaniano sobre todo lenguaje, ahora intensificado por la condición poética del lenguaje de Espriu: "Yo puedo venir al ser desapareciendo de mi dicho. (...) Es así como adviene Yo como sujeto que se conjuga por la doble aporía de una subsistencia verdadera que queda abolida por su saber y de un discurso donde es la muerte la que sostiene la existencia" (Lacan 2009: 763). La muerte sostiene la existencia, como las palabras sostienen y son sostenidas por su final, por su falta. La falta de Espriu entronca entonces con el paso de la noche, siguiendo a Badiou (2005: 190), con una "pasión de lo real como mañana del ser que se inventa en la activación de las formas". La dimensión ontológica o metafísica del ser, de hecho, es desplazada por la función poética hacia una práctica lingüística donde "el lenguaje deja de ser representativo para tender hacia sus extremos o sus límites” (Deleuze/ Guattari 1978: 39).

Lo real, el dolor y la pasión que provoca en nosotros, no se pone a distancia por el hecho de situarnos en un plano de subjetividad inconsciente, o de lenguaje lírico. Al contrario, se reincorpora a nuestra experiencia del mundo de una forma siempre nueva, humildemente nueva, siempre atenta a atravesar lo imposible, más aún cuando es el mundo el lugar por excelencia de la imposibilidad, el espacio privilegiado de la catástrofe. Si es cierto, como también sugiere Badiou, que, sin ir más lejos, "la Guerra Civil española es una miniatura interna del siglo entero" (2005: 39), entonces tal vez se entienda mejor hasta qué punto la poesía de Salvador Espriu se muestra ante nosotros todavía imposible, secreta, tan ausente como viva. Su lírica es en cierto sentido temprana no solamente con respecto a aquello que escribiría en años posteriores. Es temprana asimismo en relación con el orden de pensamiento y de realidad establecido todavía hoy. Así que tiene aún más tiempo por delante. Y demuestra con ello lo que nos hace falta.

\section{Referencias bibliográficas}

ADORNO, Th. W. (1992): Teoría estética. Madrid, Taurus. 
98 Tropelías. Revista de Teoría de la Literatura y Literatura Comparada, número extraordinario 4 (2018) Antonio Méndez Rubio

BADIOU, A. (2005): El siglo. Buenos Aires, Manantial.

BATISTA, A. (1985): Salvador Espriu: Itinerari personal. Barcelona, Empúries.

BLANCHOT, M. (1987): La escritura del desastre. Caracas, Monte Avila Editores.

CASTELLET, J. M. a (1978): Iniciació a la poesia de Salvador Espriu. Barcelona, Edicions 62.

CUESTA ABAD, J. M. (2010): La transparencia informe (Filosofía y literatura de Schiller a Nietzsche). Madrid, Abada Editores.

DELEUZE, G., y F. Guattari (1978): Kafka: Por una literatura menor. México, Era.

ESPRIU, S. (1980-81): Años de aprendizaje (Poesía 1/2/3). Trad. de Andrés Sánchez Robayna y Ramon Pinyol Balasch. Barcelona, Edicions del Mall.

FOUCAULT, M. (2015): La ética del pensamiento (Para una crítica de lo que somos). Madrid, Biblioteca Nueva.

FREUD, S. (2011): La interpretación de los sueños (I-II). Madrid, Alianza Editorial.

JAKOBSON, R. (1985): Lingüística y poética. Madrid, Cátedra.

LACAN, J. (2009): Escritos (2). México, Siglo XXI.

MALLARMÉ, S. (2002): Fragmentos sobre el libro. Murcia, Colegio Oficial de Aparejadores y Arquitectos Técnicos de la Región de Murcia.

MÉNDEZ RUBIO, A. (2008): La destrucción de la forma (y otros escritos sobre poesía y conflicto). Madrid, Biblioteca Nueva.

MÓRA, C. (1992): Salvador Espriu i Sinera. Argentona, L’Aixernador Edicions.

NOVALIS (2004): Poesías completas / Los discípulos en Sais. Barcelona, DVD.

PIERA, C. (2012): La moral del testigo (Ensayos y homenajes). Madrid, Antonio Machado Libros.

PRATS SOBREPERE, J. (1992): Salvador Espriu, missatge personal. Barcelona, Publicacions de l'Abadia de Montserrat.

WAJCMAN, G. (2001): El objeto del siglo. Buenos Aires, Amorrortu. 